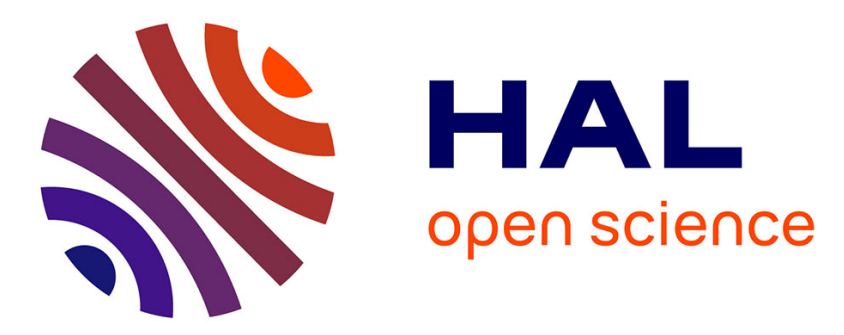

\title{
Targeting Id 1 and Id3 by a specific peptide aptamer induces E-box promoter activity, cell cycle arrest, and apoptosis in breast cancer cells
}

Demissew S. Mern, Karin Hoppe-Seyler, Felix Hoppe-Seyler, Jens Hasskarl, Barbara Burwinkel

\section{To cite this version:}

Demissew S. Mern, Karin Hoppe-Seyler, Felix Hoppe-Seyler, Jens Hasskarl, Barbara Burwinkel. Targeting Id 1 and Id3 by a specific peptide aptamer induces E-box promoter activity, cell cycle arrest, and apoptosis in breast cancer cells. Breast Cancer Research and Treatment, 2010, 124 (3), pp.623-633. 10.1007/s10549-010-0810-6 . hal-00534551

\section{HAL Id: hal-00534551 \\ https://hal.science/hal-00534551}

Submitted on 10 Nov 2010

HAL is a multi-disciplinary open access archive for the deposit and dissemination of scientific research documents, whether they are published or not. The documents may come from teaching and research institutions in France or abroad, or from public or private research centers.
L'archive ouverte pluridisciplinaire HAL, est destinée au dépôt et à la diffusion de documents scientifiques de niveau recherche, publiés ou non, émanant des établissements d'enseignement et de recherche français ou étrangers, des laboratoires publics ou privés. 
Demissew S. Mern*1, Karin Hoppe-Seyler ${ }^{2}$, Felix Hoppe-Seyler ${ }^{2}$, Jens Hasskarl ${ }^{\dagger 3}$ and Barbara Burwinkel ${ }^{\dagger 1,4}$

\section{Targeting Id1 and Id3 by a Specific Peptide Aptamer Induces E-Box} 5 Promoter Activity, Cell Cycle Arrest and Apoptosis in Breast Cancer Cells

${ }^{1}$ Helmholtz-University Group Molecular Epidemiology, German Cancer Research Center, Im Neuenheimer Feld 581, D-69120 Heidelberg, Germany

${ }^{2}$ Molecular Therapy of Virus-Associated Cancers, German Cancer Research Center,

Im Neuenheimer Feld 242, D-69120 Heidelberg, Germany

${ }^{3}$ Division of Hematology and Oncology, University of Freiburg Medical Center, Hugstetter Strasse 55, D-79106 Freiburg im Breisgau, Germany

${ }^{4}$ Division Molecular Biology of Breast Cancer, Department of Gynecology and Obstetrics, University of Heidelberg, Voss Strasse 9, D-69120 Heidelberg, Germany

*To whom correspondence should be addressed:

Postal address: Demissew S. Mern, Helmholtz-University Group Molecular Epidemiology, German Cancer Research Center, Im Neuenheimer Feld 581, D-69120 Heidelberg, Germany

E-mail: d.mern@dkfz-heidelberg.de Phone: +49 6221 421461/2 Fax: +496221 421464

${ }^{\dagger}$ Equal contribution. 


\section{ABSTRACT}

Inhibitors of differentiation or DNA binding (Id) proteins have been shown to be involved in tumor growth, invasiveness, metastasis and angiogenesis. Overexpression of Id proteins, especially Id1, correlates with unfavorable clinical prognosis. Thus, they are attractive molecular targets for anti-cancer therapy. Overexpression of Id proteins mediates breast cancer metastasis to lung. Targeting Id1 and Id3 expression in breast cancer cells reduces breast cancer metastasis in animal models. Different breast tumors failed to grow and/or metastasize in $I d 1^{+/} I d 3^{-/}$mice. Id1 and Id3 preferentially dimerize with the key regulatory Eproteins and inhibit the expression of different tumor suppressor genes. Nevertheless, the inhibition of tumorigenic activities of Id1 and Id3 at protein level has never been studied.

Here, we isolated a novel peptide aptamer, Id1/3-PA7, specifically interacting with Id1 and Id3 from randomized combinatorial expression library using yeast and mammalian two hybrid systems.

Intracellular delivered Id1/3-PA7 co-localized to Id1 and Id3 and interfered with their functions. It repressed E47 protein sequestration by $\operatorname{Id} 1$ and Id3, activated the E-box promoter and increased the expression level of cyclin-dependent kinase inhibitors (CDKN1A and CDKN1B) in a dose dependent fashion, paralleled by the cleavage of poly ADP ribose polymerase (PARP). These effects were counteracted by ectopically overexpressed Id1 and Id3. Peptide aptamer Id1/3-PA7 induced cell cycle arrest and apoptosis in breast cancer cells MCF7 and MDA-MB-231.

In conclusion, Id1/3-PA7 could represent a non-toxic exogenous agent that can significantly provoke antiproliferative and apoptotic effects in breast cancer cells, which are associated with deregulated expression of Id1 and Id3.

25 Key words: peptide aptamer, Id1 and Id3, breast cancer, cell cycle arrest, apoptosis 


\section{INTRODUCTION}

The inhibitors of differentiation or DNA binding proteins (Id1-4) are dominant inhibitors of helix-loop-helix (HLH) transcription factors. They inhibit the activities of several classes of basic helix-loop-helix (bHLH) transcription factors [1], retinoblastoma (Rb) "pocket" proteins [2], Ets domain proteins [3] and Pax homeodomain containing proteins [4]. Their interference with the key regulatory bHLH proteins is established as an important interaction for cell cycle regulation [1]. In most cases, Id1 and Id3 interact exclusively with class A bHLH proteins. Within class A members, they preferentially dimerize with E-proteins: E12/E47, E2-2 and HEB [5]. While E-proteins activate transcription by binding to promoter E-boxes, Id proteins lacking basic DNA binding domain form DNA binding incompetent heterodimers with Eproteins. This leads to the transcriptional repression of different cell cycle regulators, which implies important roles of Ids for cell fate decision of growth and differentiation [6-7].

Expression of Id proteins is typically high in actively proliferating cells and is down-regulated as a prerequisite for exit from the cell cycle and terminal differentiation [8-9]. Id proteins promote cell proliferation by regulating the expression of genes or activities of proteins involved in cell cycle such as the cyclin-dependent kinase inhibitors CDKN1A [10], CDKN1B [11], CDKN2A [12] and the retinoblastoma tumor suppressor protein pRb [2]. Upregulated Id activity is tumorigenic [11]. Overexpression of Id proteins, especially Id1, is frequently found in several human malignancies including breast cancer, and seems to correlate with unfavorable clinical prognosis [13-16]. The low postnatal expression of Ids and their roles in tumorigenesis, tumor invasiveness, metastasis and neoangiogenesis mark them as attractive targets for anti-cancer therapy [11]. Inhibition studies have shown that the functions of Id proteins can be down-regulated through Id-specific antisense oligonucleotides or small interference RNAs and their down-regulation can cause growth arrest and induction of apoptosis in various tumor cells [11]. Targeting Id1 expression in breast cancer cells reduces breast cancer metastasis in animal models [17-18]. Mice lacking Id1/Id3 genes are 
resistant to xenotransplanted tumor grafts and show defects in tumor neoangiogenesis [19]. Different breast tumors failed to grow and/or metastasize in $\operatorname{Id} 1^{+/-} \operatorname{Id}^{-/-}$mice [20].

So far the functions of Id1 and Id3 have been inhibited only through interference at DNA or RNA levels. Based on these observations the present study was designed to identify peptide aptamers having the potential to block the intracellular functions of Id proteins. Peptide aptamers represent short peptides of random sequences. Based on their in vivo binding affinity to their target protein, they can be selected from randomized combinatorial expression libraries using yeast and mammalian two hybrid systems [21-23]. They bear some analogies with the monoclonal antibodies, with the advantage that they are isolated with their coding sequences and their small size would allow to elucidate their structure. Peptides delivered into cells by protein transduction domains can selectively inhibit the activities of their target proteins in a dose- and time-dependent fashion [24-25]. Thus, they represent powerful alternative tools to the approaches of the antibody based inhibition model or siRNA based gene silencing method.

Here, we present a novel peptide aptamer, Id1/3-PA7, specifically interacting with Id1 and Id3. It inhibited the heterodimerization of E47 with Id1 or Id3, enhanced E-box promoter activity and elevated the expression of tumour suppressors CDKN1A and CDKN1B in a dose dependent manner. It induced additionally PARP cleavage. Id1/3-PA7 exacerbated both cell cycle arrest and apoptosis in breast cancer cells. 


\section{MATERIALS AND METHODS}

\section{Cell Lines and Cell Culture}

MCF7 and MDA-MB-231 cell lines were purchased in October 2007 from the American Type Culture Collection (ATCC, Manassas, USA). HeLa cell line was purchased in

5 November 2007 from German Collection of Microorganisms and Cell Cultures (DSMZ, Braunschweig, Niedersachsen, Germany). MCF7 and HeLa cell lines were grown in EMEM (ATCC) and MDA-MB-231 cell lines in Leibovitz's L-15 Medium (ATCC). Growth media EMEM and Leibovitz's L-15 were supplemented with $10 \%$ fetal bovine serum (ATCC), penicillin $(50 \mathrm{U} / \mathrm{ml})$, streptomycin $(50 \mathrm{mg} / \mathrm{ml})$ and $2 \mathrm{mM}$ glutamine (Sigma, Deisenhofen, Bayern, Germany). For growing of MCF7 cell lines $5 \mathrm{mg} / \mathrm{ml}$ insulin (Sigma) was added and MDA-MB-231 cell lines were grown in $100 \%$ atmospheric air without $\mathrm{CO}_{2}$. All cell lines were tested and authenticated in February 2008 by the Genetic Core Facility at German Cancer Research Center using the method Multiplex cell Contamination Test (McCT) (Ref. http://www.dkfz.de/gpcf/contamination-control.html).

\section{Transfections}

For luciferase assays HeLa and MCF7 cells were transiently transfected using calcium phosphate method [26]. For the analysis of PARP cleavage or CDKN1A and CDKN1B expressions MCF7 and MDA-MB-231 cells were transfected using the FuGENE 6 Transfection Reagent (Roche Molecular Biochemicals, Indianapolis, USA). Cells were selected with 1mg/ml G418 (Sigma, Deisenhofen, Bayern, Germany). Transfections were monitored by immunoblot detection of the expressed proteins.

\section{Yeast Two-Hybrid Screening of Peptide Aptamers}

The screening was done in the yeast strain MaV203 (MATa, leu2-3,112, trp1-901, his3 $\Delta 200$,

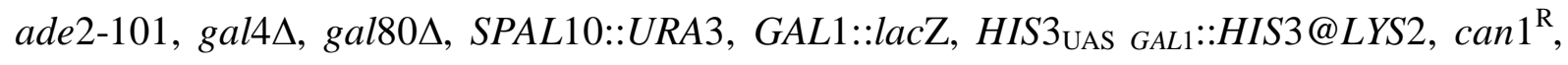


$\left.c y h 2^{\mathrm{R}}\right)$. As baits, full length of human Id1, Id2 and Id3 were fused to the GAL4-DBD into the pPC97 vector (pPC97-Id1, pPC97-Id2 or pPC97-Id3). Screenings were done with randomized constrained peptide aptamer library (pADtrx-aptamers) and selection procedures were performed as described previously [21].

\section{Mammalian Two-Hybrid Screening of Peptide Aptamers}

For mammalian two-hybrid assays the CheckMate Mammalian Two-Hybrid System (Promega Corporation, Madison, USA) was used. Peptide aptamers and Id genes were subcloned into vectors pACT and pBIND as prey and bait respectively. In bait constructs Ids (Id1-4) were fused to a GAL4-DBD and in prey constructs peptide aptamers or TrxA were fused to a VP16-TAD. The luciferase reporter gene construct pG5luc was used, which is under the control of the GAL4-DBS. HeLa cells were transfected with bait, prey, and luciferase reporter vectors along with pCMV-LacZ as an internal standard. Forty-two hours after transfection cells were lysed in Triton buffer [1\% Triton X-100, $25 \mathrm{mM}$ glycylglycin (pH 7.8), $15 \mathrm{mM} \mathrm{MgSO}_{4}, 4 \mathrm{mM}$ EGTA and $1 \mathrm{mM}$ DTT] for $10 \mathrm{~min}$ on ice. The lysates were clarified by centrifugation for $10 \mathrm{~min}$ at $16000 \mathrm{x}$ g. Lysates $(10 \mu \mathrm{l})$ were measured using a luminometer (Berthold, Vista, USA) by injecting luciferin reagent $[25 \mathrm{mM}$ glycylglycin ( $\mathrm{pH}$ 7.8), $5 \mathrm{mM}$ ATP (pH 7.8) and $330 \mathrm{mM}$ beetle luciferin]. The samples were normalized for the $\beta$-galactosidase activity, which was measured after incubating $3 \mu 1$ lysate with $33 \mu 1$ reaction buffer [100 mM Na $2 \mathrm{HPO}_{4}, 1 \mathrm{mM} \mathrm{MgCl}$ and 1 x Galacton (Tropix, Bedford, USA)] for 30 min in dark. The galactosidase activity was measured in a luminometer by injection of amplifier [10\% Emerald (Tropix), $0.2 \mathrm{M} \mathrm{NaOH}]$.

\section{Bacterial Expression and Purification of PTD Fused Peptide Aptamers}

A protein transduction domain (PTD), truncated VP22 ORF [24-25] was used for the intracellular delivery of the peptide aptamer. PTD was fused to the C-terminus of the peptide 
aptamers or TrxA, which were inserted into the vectors, pCR T7/VP22-1-TOPO and pCR T7/VP22/NES-2-TOPO (Invitrogene, Carlsbad, USA). Bacterial expression of the peptide aptamer was induced with isopropyl-1-thio- $\beta$-D-galactopyranoside $(1 \mathrm{mM})$ for $5 \mathrm{~h}$ at room temperature. The peptide aptamers were furnished with 6xHis-tag to facilitate their

5 purification by nickel chelate chromatography. Purification of the peptide aptamer was done under native conditions using ProBond Purification System (Invitrogene, Carlsbad, USA). The purity of the peptide aptamer was investigated by gel electrophoresis and coomassie staining. The concentration was determined by BCA Protein Assay Kit (Pierce, Rockford, USA).

\section{Immunofluorescence and Immunoblotting}

For immunofluorescence analysis, cells were grown on cover slips, fixed and permeabilized in methanol for $20 \mathrm{~min}$ at $-20^{\circ} \mathrm{C}$ and rehydrated with PBS. Before immunostaining with the indicated antibodies, cells were blocked in normal serum (1:10 in PBS containing 5\% BSA). Nuclei were visualized by using Prolong Gold Antifade Reagent with DAPI (Invitrogene, Carlsbad, USA). Cells were analysed using Carl Zeiss AxioVision 4 microscope equipped with Carl Zeiss AxioCam digital camera and software version Carl Zeiss AxioVision Rel. 4.6.3 (Carl Zeiss Vision GmbH, Jena, Thueringen, Germany).

For immunoblot experiments, cell lysates prepared in EBC buffer (50mM Tris-HCl, $120 \mathrm{mM}$ $\mathrm{NaCl}, 1 \%(\mathrm{v} / \mathrm{v})$ Nonidet $\mathrm{P} 40, \mathrm{pH} 8.0$ ) supplemented with protease and phosphatase inhibitors were separated by SDS-PAGE and electrotransferred to polyvinylidene fluoride membranes (Millipore, Temecula, USA). To detect antigen/antibody complexes membranes were incubated with appropriate horseradish peroxidase-labeled secondary antibodies (Santa Cruz Biotechnology, Santa Cruz, USA) and developed for enhanced chemiluminescence using the ECL WB Detection Kit (Millipore, Temecula, USA). 
Primary antibodies used were anti-Id1 (C-20), anti-Id3 (C-20) (Santa Cruz Biotechnology, Santa Cruz, USA), anti- $\alpha$ tubulin, anti-Trx (Sigma, Deisenhofen, Bayern, Germany), antiCDKN1A, anti-CDKN1B (Millipore, Temecula, USA) and anti-PARP (BD Biosciences, San Jose, USA). Secondary antibodies used were goat anti-mouse or goat anti-rabbit Alexa Fluor 488, 660 and 680 for immunofluorescence experiments and HRP-conjugated goat anti rabbit and goat anti mouse (Santa Cruz Biotechnology, Santa Cruz, USA) for immunoblotting.

\section{Coimmunoprecipitation}

MCF7 and MDA-MB-231 cells were treated with peptide aptamer Id1/3-PA7 (5 $\mu \mathrm{g} / 10^{6}$ cells). After $1.5 \mathrm{~h}$ cells were lysed in RIPA Buffer (Pierce, Rockford, USA) containing protease and phosphatase inhibitors. Protein samples were purified by nickel chelate chromatography under native conditions using ProBond Purification System (Invitrogene, Carlsbad, USA) and analysed by western blotting using antibodies against Trx, Id1 and Id3.

\section{E-Box Promoter-Reporter Assays}

pGL4.1-4Rtk-luc (E-box-dependent-reporter-construct), pcDNA3-E47, pCMV-Id1, pCMVId3 along with pCMV-LacZ as an internal standard were used for transfection of MCF7 cells. After transfection cells were treated by adding Id1/3-PA7 $\left(5 \mu \mathrm{g} / 10^{6}\right.$ cells $)$ in 4 h intervals for $48 \mathrm{~h}$. Cell lysis and measurement of luciferase activity were done as described in the above experiment of mammalian two-hybrid assays.

\section{RNA Analysis}

Cells were treated with different doses of Id1/3-PA7 $\left(1-7.5 \mu \mathrm{g} / 10^{6}\right.$ cells $)$ in $4 \mathrm{~h}$ intervals for 48 h. Total RNA was purified using RNeasy Plus Mini Kit (QIAGEN, Hilden, NordrheinWestfalen, Germany) and inspected by agarose gel electrophoresis. cDNAs were synthesized using TaqMan Reverse Transcription Reagents (Applied Biosystems, Foster City, USA). The 
mRNAs of CDKN1A, CDKN1B and $\beta$-Actine as internal standard were measured by real time PCR with TaqMan gene expression assays (Applied Biosystems) using the LightCycler 480 Real-Time PCR System and LightCycler 480 Probes Master (Roche Applied Science, Mannheim, Baden-Wuerttemberg, Germany ). Program: 15 min at $95^{\circ} \mathrm{C}$ activation, 40 cycles

5 of $15 \mathrm{~s}$ at $95^{\circ} \mathrm{C}$ followed by $30 \mathrm{~s}$ at $55^{\circ} \mathrm{C}$ and $1 \mathrm{~s}$ at $72^{\circ} \mathrm{C}$, melting $1 \mathrm{~s}$ at $55^{\circ} \mathrm{C}$ and cooling 1 $\min$ at $40^{\circ} \mathrm{C}$. For the relative quantification of the mRNA levels three independent amplifications were performed for each probe, with triplicate samples. The relative mRNA levels were numerically presented using the comparative $2^{-\Delta \Delta c}$ T method.

\section{Flow Cytometry Cell Cycle Analysis}

Cells were treated with Id1/3-PA7 $\left(5 \mu \mathrm{g} / 10^{6}\right.$ cells) in $4 \mathrm{~h}$ intervals for $48 \mathrm{~h}$. For quantitative cell cycle analysis, BD Pharmingen FITC BrdU Flow Kit (BD Biosciences, San Jose, USA) was used. Prolonged cell exposure $(6 \mathrm{~h})$ to BrdU allowed identification and analysis of actively cycling, as opposed to non-cycling, cell fractions. The measurement of cell incorporated BrdU (with FITC anti-BrdU) and total DNA content (with 7-AAD) in cells was performed using the BD FACSCalibur Flow Cytometer (BD Biosciences, San Jose, USA). 


\section{RESULTS}

\section{Screening of Id Protein Specific Peptide Aptamers}

Using yeast two-hybrid system, we aimed to identify peptide aptamers that would specifically bind to Id proteins. For screening of peptide aptamers, we used a yeast two-hybrid peptide 5 aptamer expression library encoding $2 \times 10^{8}$ random peptides of 20 amino-acid, which are displayed by the active-site loop of Escherichia coli thioredoxin (TrxA). Using wild type Id1 as bait construct subsequently transformed with expression vectors encoding the random peptide library in yeast strain MaV203, which contains three selectable markers (His3, Ura3 and LacZ) under the control of three different GAL4 binding promoter regions, we isolated 37 positive hits from the library. We sequenced the peptide aptamers from all 37 clones and identified 30 clones of different peptide aptamers (Tab. 1), which grew in the absence of uracil, histidine and were blue on selection plate containing X-Gal. As Id proteins exhibit high sequence homologies within their HLH-domains, have common binding partners and partially overlapping functions, we examined whether the isolated 30 peptide aptamers also interact with Id2 and Id3. We found that one of the peptide aptamers also interacted with Id2 and six peptide aptamers interacted with Id3 (Tab. 1). Id4 was not used for the yeast two-hybrid screen as its expression as bait in yeast MaV203 could not be verified. In negative controls there was no interaction between Ids and the empty prey vector pADtrx and no interaction between peptide aptamers and the empty bait vector pPC97 (Tab. 1). Blast searches with all identified peptide aptamers revealed no sequence similarities with known proteins. All Idbinding peptide aptamers did not show more than random similarity to any other. 


\section{Specific interaction of the peptide aptamers with Id Proteins in human cells}

To confirm the interaction of in yeast two-hybrid selected peptide aptamers with Id proteins in human cells, mammalian two-hybrid experiments in HeLa cells were performed. All 30 peptide aptamers and all four $I d$ genes were subcloned into mammalian expression vectors pACT and pBIND as prey and bait respectively. We used the luciferase reporter gene construct pG5luc, which is under the control of the GAL4-DBS. HeLa cells were transfected with bait, prey, and luciferase constructs along with pCMV-LacZ as an internal standard. Interactions of peptide aptamer 5 (Id1-PA5) and peptide aptamer 17 (Id1-PA17) with Id1, peptide aptamer 7 (Id1/3-PA7) with Id1 and Id3, peptide aptamer 10 (Id3-PA10) with Id3 and peptide aptamer 13 (Id1-4-PA13) with all Ids were verified (Fig. 1a). Our goal was obtaining peptide aptamers that bind to Id proteins but not to their binding partners. Accordingly, we tested the interaction of the five peptide aptamers with Id binding proteins. None of the five peptide aptamers interacted with E47, MyoD, ETS1, ETS2 and S5A (Fig. 1b).

\section{Id1/3-PA7 induces E-box promoter activity}

The mere binding ability of the peptide aptamers to Id proteins does not necessarily imply functional interference with the Ids. For the intracellular delivery, the peptide aptamers and TrxA were cloned in to vectors pCR T7/VP22-1-TOPO and pCR T7/VP22/NES-2-TOPO to express them in fusion with cell penetrating PTD [24-25]. Although all recombinant peptide aptamers and TrxA were expressed in bacteria, only Id1/3-PA7 and TrxA were successfully purified under native conditions. Breast cancer cells MDA-MB-231 and MCF7 (cultured in $10 \%$ serum) overexpressing Id1 and Id3 were treated with Id1/3-PA7 (5 $\mu \mathrm{g} / 10^{6}$ cells). $1.5 \mathrm{~h}$ after treatment the internalization of the peptide aptamer into cells and its colocalization with Id1 and Id3 was verified by His-tag coimmunoprecipitation (Fig. 2a-b). TrxA treated cells were used as negative control (Fig. 2c-d). Additionally we verified its colocalization with Id1 and Id3 by coimmunofluorescence staining in MCF7 cells (Fig. 2e-f). Id1/3-PA7 untreated 
MCF7 cells were used as negative control (Fig. 2g). To analyze the potency of Id1/3-PA7 with respect to Id1 and Id3 inhibition and restoration of E-box promoter activity, we used the E-box-dependent reporter gene 4Rtk-luc, which contains four tandem E-boxes from the MCK enhancer upstream of the thymidine kinase basal promoter [27]. MCF7 cells were transfected with 4Rtk-luc, pcDNA3-E47, pCMV-Id1, pCMV-Id3 and pCMV-LacZ as an internal standard. After transfection cells were treated with Id1/3-PA7 $\left(5 \mu \mathrm{g} / 10^{6}\right.$ cells, half-life $\left.2.5 \mathrm{~h}\right)$ in $4 \mathrm{~h}$ intervals for $48 \mathrm{~h}$. The reporter gene was upregulated in the presence of E47. E47 dependent activation was reduced in the presence of $\operatorname{Id} 1$ or Id 3 and by addition of Id1/3-PA7, the activation was restored again (Fig. 2h). Treatment of cells with TrxA (5 $\mu \mathrm{g} / 10^{6}$ cells) had no any effect on the E-box promoter activity (Fig. 2h).

\section{Id1/3-PA7 upregulates expression of CDKN1A and CDKN1B}

E-proteins activate transcription by binding to promoter E-boxes. Formation of heterodimers between Id protein and E-protein prevents E-proteins from forming DNA-binding transcriptionally active complexes. This inhibits E-box promoter dependent transcriptional activation of the tumor suppressor genes $C D K N 1 A$ and $C D K N 1 B$. We analyzed the effects of Id1/3-PA7 on expression levels of CDKN1A and CDKN1B by real time PCR and western blotting. Breast cancer cells MCF7 and MDA-MB-231 were treated with different doses of Id1/3-PA7 (1-7.5 $\mu \mathrm{g} / 10^{6}$ cells) in $4 \mathrm{~h}$ intervals for $48 \mathrm{~h}$. Transduction of Id1/3-PA7 caused to that in untreated or TrxA treated cells (Fig. 3a-d). These increased expression levels of CDKN1A and CDKN1B were counteracted by ectopically overexpressed Id1 and Id3 (Fig. $3 a-b)$. 


\section{Id1/3-PA7 Induces Cell Cycle Arrest and Apoptosis in Breast Cancer Cells}

CDKN1A and CDKN1B block cell cycle progression by inhibiting the activities of cyclin dependent kinases [28-29] and prevent DNA synthesis by interacting with the proliferating cell nuclear antigen [30]. Using flow cytometry we analysed the effects of Id1/3-PA7 on cell cycle progression and apoptosis in breast cancer cells MCF7 and MDA-MB-231. Cells were treated with Id1/3-PA7 (5 $\mu \mathrm{g} / 10^{6}$ cells) in $4 \mathrm{~h}$ intervals for $48 \mathrm{~h}$. For the identification and analysis of actively cycling, as opposed to non-cycling, cell fractions, we prolonged the exposure of untreated and TrxA or Id1/3-PA7 treated cells to BrdU for $6 \mathrm{~h}$. The cell cycle positions and active DNA synthetic activities of cells were determined by analysing the correlated expression of total DNA and incorporated BrdU levels as shown by the region gates applied to the 7-AAD versus BrdU dot plot (Fig. 4a-f). Flow cytometric analysis of untreated cells versus Id1/3-PA7 treated cells showed that the antiproliferative and apoptotic effects of Id1/3-PA7 reduced the number of actively cycling cells in S from $92.1 \%$ to $51.1 \%$ for MCF7 cells (Fig. 4g) and from $92.5 \%$ to $53.5 \%$ for MDA-MB-231 cells (Fig. 4i). The number of apoptotic cells in sub G0/G1 and in G0/G1 or in G2/M resided cells increased from $2.1 \%$ to $15 \%$, from $3.9 \%$ to $19 \%$ and from $0.3 \%$ to $5.3 \%$ respectively for MCF7 cells (Fig. $4 \mathrm{~h}$ ) and from $0.9 \%$ to $13 \%$, from $2.7 \%$ to $18.1 \%$ and from $0.4 \%$ to $7.6 \%$ respectively for MDAMB-231 cells (Fig. 4j). There were no significant differences between flow cytometric results of untreated and TrxA treated cells (Fig. 4a-j).

Recently, it has been shown that treatments of different cancer cell lines with different anticancer drugs, which led to increased apoptosis rates and increased cleaved PARP were associated with downregulation of Id1 expression at both transcriptional and protein levels [31]. Ectopically overexpressed Id1 was able to suppress PARP cleavage in response to anticancer drugs [31]. Therefore, we analysed the cleavage of PARP in Id1/3-PA7 treated MCF7 and MDA-MB-231 cells versus untreated or TrxA treated cells. By western blotting we detected PARP cleavage in cell extracts of Id1/3-PA7 treated cells using anti-PARP 
antibody, which recognizes uncleaved PARP (113 kDa) and cleaved PARP (85 kDa) (Fig. 5ab). PARP cleavage was counteracted in Id1/3-PA7 treated cells by ectopically overexpressed Id1 and Id3 (Fig. 5c-d).

\section{DISCUSSIONS}

A similar expression pattern of Id 1 and Id 3 in many human breast cancers of various grades has been characterized [19]. The genetics of the $I d I$ and $I d 3$ knockouts clearly indicate that partial loss of Id functions is sufficient in some settings to have a therapeutic effect. Mice lacking Id1/Id3 genes are resistant to xenotransplanted tumor grafts and show defects in tumor neoangiogenesis [19]. Different tumors, including B6RV2 and MMTV-HER2/neu breast cancers, failed to grow and/or metastasize in $\mathrm{Id}^{+/-} \mathrm{Id} 3^{-/-}$mice [20]. Therefore, parallel inhibition of Id1 and Id 3 could be a promising and effective treatment approach.

Overlapping expression of Ids during cell cycle progression and their differences in binding specificities as well as regulation by phosphorylation underline different functions of Id proteins in cell cycle control. Upregulated Id activity is tumorigenic and contributes to hallmarks of malignancy. The low postnatal expression of the Ids and their roles in tumorigenesis and tumor neoangiogenesis mark them as attractive targets for anti-cancer therapy [11]. Metastasis, where Id proteins are highly overexpressed, is the final and fatal step in the progression of cancer [13-16]. Therapeutic strategies, which are currently available at this stage of cancer progression, are usually none specific, highly toxic and have only marginal efficacy. This is in part due to the lack of knowledge about the molecular mechanisms regulating the development of aggressive cancers. Approaches targeting Id expression, including gene therapy using antisense oligonucleotide, short interfering RNA, and nonviral or viral plasmid-based strategies, could have undesired biological outcomes, as 
they are not able to discriminate among functional domains of a protein, which could be involved in different biological interactions and disease relevant phenotypes. Therefore, peptide based therapeutic approaches targeting specific mechanisms involved in the development of aggressive cancers are needed. Id proteins are expressed at very low levels in normal adult tissues and overexpressed in cancer cells, excluding thereby unwanted toxicities generally associated with currently available therapeutic modalities. Recently it has been reported that a peptide-conjugated Id1 antisense oligonucleotide homed to tumor neovessels downregulates Id1 in tumor endothelial cells in vivo and inhibits primary tumor growth and metastasis of aggressive breast cancers in two different murine models [32]. More recently it has been shown that targeting Id2 in human neuroblastoma cells using the HLH domain 13I, which is isolated from a phage display library of HLH domains, induces neuroblastoma cell differentiation that may restrain neuroblastoma cell tumorigenicity [33].

Here we demonstrated for the very first time a specific, effective and joint inhibition of Id1 and Id 3 activities at protein level using a peptide aptamer Id1/3-PA7. The combined inhibition might be very important due to the fact that Id1 and Id3 have partial overlapping functions, are expressed in parallel and might compensate for each other. Therefore, combined targeting of Id1 and Id 3 could be a promising approach to treat tumors, which are associated with deregulated expression of Id1 and Id3. Id1/3-PA7 exerted in breast cancer cells MCF7 and MDA-MB-231 antiproliferative and apoptotic effects involving E-box promoter activation, upregulation of CDKN1 A and CDKN1B, which is paralleled by the cleavage of PARP.

We propose that the use of Id1/3-PA7, as inhibitor of Id 1 and Id 3 activities, could represent a novel strategy to treat breast cancer and possibly other cancers, as expression of Id proteins, especially Id1, has been found to be upregulated during the progression of different types of solid tumors [34-35]. It could represent an alternative tool to the approaches of the antibody based inhibition model or siRNA based gene silencing method. It could be used as drug leads 
to create more potent and efficacious peptide mimetics and non-peptide drugs with higher metabolic stability, bioavailability and biological activity.

\section{Acknowledgments}

We thank R. Benezra (Sloan-Kettering Institute for Cancer Research, New York, USA) for providing plasmids pGL4.1-4Rtk-luc and pcDNA3-E47 and S. Schmitt (Core Facility Flow Cytometry, DKFZ) and S. Poppelreuter (Carl Zeiss MicroImaging GmbH) for supporting in cell cycle profiling and fluorescence microscopy. This study was supported by the Deutsche Forschungsgemeinschaft (grant HA3185/2-1 and 2-3), the Helmholtz Society (grant VH-NG213) and the German Cancer Research Center. 


\section{REFERENCES}

1. Benezra R, Davis RL, Lockshon D, Turner DL, Weintraub H (1990) The protein Id: a negative regulator of helix-loop-helix DNA binding proteins. Cell 61:49-59

2. Iavarone A, Garg P, Lasorella A, Hsu J, Israel MA (1994) Helix-loop-helix protein Id-2

5 enhances cell proliferation and binds to the retinoblastoma protein. Genes Dev 8:12701284

3. Yates PR, Atherton GT, Deed RW, Norton JD, Sharrocks AD (1999) Id helix-loop-helix proteins inhibit nucleoprotein complex formation by the TCF ETS-domain transcription factors. EMBO J 18:968-76

10 4. Roberts CE, Deed RW, Inoue T, Norton JD, Sharrocks AD (2001) Id helix-loop-helix proteins antagonize pax transcription factor activity by inhibiting DNA binding. Mol Cell Biol 21:524-533

5. Langlands K, Yin X, Anand G, Prochownik EV (1997) Differential interactions of Id proteins with basic-helix-loop-helix transcription factors. J Biol Chem 272:19785-19793

15 6. Ruzinova MB, Benezra R (2003) Id proteins in development, cell cycle and cancer. Trends Cell Biol 13:410-418

7. Yokota Y, Mori S (2002) Role of Id family proteins in growth control. J Cell Physiol $190: 21-28$

8. Barone MV, Pepperkok R, Peverali FA, Philipson L (1994) Id proteins control growth 20 induction in mammalian cells. Proc Natl Acad Sci USA 91:4985-4988

9 Peverali FA, Ramqvist T, Saffrich R, Pepperkok R, Barone MV, Philipson L (1994) Regulation of G1 progression by E2A and Id helix-loop-helix proteins. EMBO J 13:4291301

10. Prabhu S, Ignatova A, Park ST, Sun XH (1997) Regulation of the expression of cyclindependent kinase inhibitor p21 by E2A and Id proteins. Mol Cell Biol 17:5888-96 
11. Perk J, Iavarone A, Benezra R (2005) ID Family of Helix-Loop-Helix Proteins in Cancer. Nat Rev Cancer 5:603-614.

12. Alani RM, Young AZ, Shifflett CB (2001) Id1 regulation of cellular senescence through transcriptional repression of p16/Ink4a. Proc Natl Acad Sci USA 98:7812-7816

5 13. Schindl M, Oberhuber G, Obermair A, Schoppmann SF, Karner B, Birner P (2001) Overexpression of Id-1 protein is a marker for unfavorable prognosis in early-stage cervical cancer. Cancer Res 61:5703-5706.

14. Schindl M, Schoppmann SF, Strobel T, Leisser C, Birner P, Horvat R (2003) Level of Id-1 protein expression correlates with poor differentiation, enhanced malignant potential, and more aggressive clinical behavior of epithelial ovarian tumors. Clin Cancer Res 9:779-785.

15. Straume O, Akslen LA (2005) Strong expression of ID1 protein is associated with decreased survival, increased expression of ephrin-A1/EPHA2, and reduced thrombospondin-1 in malignant melanoma. Br J Cancer 93:933-938

16. Schoppmann SF, Schindl M, Bayer G et al (2003) Overexpression of Id-1 is associated with poor clinical outcome in node negative breast cancer. Int J Cancer 104:677-682

17. Fong S, Itahana Y, Sumida T et al (2003) Id-1 as a molecular target in therapy for breast cancer cell invasion and metastasis. Proc Natl Acad Sci USA 100:13543-13548

18. Minn AJ, Gupta GP, Siegel PM et al (2005) Genes that mediate breast cancer metastasis to lung. Nature 436:518-524

20 19. de Candia P, Solit DB, Giri D et al (2003) Angiogenesis impairment in Id-deficient mice cooperates with an Hsp90 inhibitor to completely suppress HER2/neu-dependent breast tumors. Proc. Natl. Acad. Sci. USA 100:12337-12342

20. Lyden D, Young AZ, Zagzag D et al (1999) Id1 and Id3 are required for neurogenesis, angiogenesis and vascularization of tumor xenografts. Nature 401:670-677 
21. Butz K, Denk C, Ullmann A, Scheffner M, Hoppe-Seyler F (2000) Induction of apoptosis in human papillomavirus positive cancer cells by peptide aptamers targeting the viral E6 oncoprotein. Proc Natl Acad Sci USA 97:6693-6697

22. Butz K, Denk C, Fitscher B et al (2001) Peptide aptamers targeting the hepatitis B virus core protein: a new class of molecules with antiviral activity. Oncogene 20:6579-6586

23. Chattopadhyay A, Tate1 SA, Beswick RW, Wagner SD, Ferrign PK (2006) A peptide aptamer to antagonize BCL-6 function. Oncogene 25:2223-2233.

24. Elliott G, O'Hare P (1997) Intercellular Trafficking and Protein Delivery by a Herpes virus. Structural Protein. Cell 88:223-233

25. Phelan A, Elliott G, O'Hare P (1998) Intercellular Delivery of Functional p53 by the Herpes virus Protein VP22. Nature Biotechnol 16:440-443

26. Chen C, Okayama H (1987) High-efficiency transformation of mammalian cells by plasmid DNA. Mol Cell Biol 7:2745-2752

27. Weintraub H, Davis R, Lockshon D, Lassar A (1990) Muscle-specific transcriptional activation by MyoD. Proc Natl Acad Sci USA 87:5623-5627

28. Zi X, Grasso AW, Kung HJ, Agarwal R (1998) A flavonoid antioxidant, silymarin, inhibits activation of erbB1 signaling and induces cyclin-dependent kinase inhibitors, G1 arrest, and anticarcinogenic effects in human prostate carcinoma DU145 cells. Cancer Res 58:1920-1929

29. Robson CN, Gnanapragasam V, Byrne RL, Collins AT, Neal DE (1999) Transforming growth factor-beta1 up-regulates p15, p21 and p27 and blocks cell cycling in G1 in human prostate epithelium. J Endocrinol 160:257-266

30. Waga S, Hannon GJ, Beach D, Stillman B (1994) The p21 inhibitor of cyclin-dependent kinases controls DNA replication by interaction with PCNA. Nature 369:574-578 
31. Xiaomeng Z, Ming-Tat L, Yong-Chuan W, Xianghong W (2007) Evidence of a novel antiapoptotic factor: Role of inhibitor of differentiation or DNA binding (Id-1) in anticancer drug-induced apoptosis. Cancer Sci 98:308-314

32. Henke E, Perk J, Vider J et al (2008) Peptide-conjugated antisense oligonucleotides for targeted inhibition of transcriptional regulator in vivo. Nat Biotechnol 26:91-100

33. Ciarapica R, Annibali D, Raimondi L, Savino M, Nasi S, Rota, R (2009) Targeting Id protein interactions by an engineered HLH domain induces human neuroblastoma cell differentiation. Oncogene 28:1881-1891

34. Downward J (2003) Targeting RAS signalling pathways in cancer therapy. Nat Rev Cancer $3: 11-22$

35. Ling MT, Wang X, Zhang X, Wong YC (2006) The multiple roles of Id-1 in cancer progression. Differentiation 74:481-487 


\section{TABLE AND FIGURES}

Tab. 1 Interactions of peptide aptamers with Id proteins in yeast. 30 peptide aptamers (PA1 30) interacting with Id1 were screened using yeast two-hybrid system. One of the peptide aptamers (PA30) interacted also with Id2 and six of the peptide aptamers (PA6-10 and PA13) interacted with Id3. Negative control: Interactions of peptide aptamers with the empty vector pPC97, and interactions Id proteins with the empty vector pADtrx.

Fig. 1 Specific interactions of the peptide aptamers with Ids in human cells. a, In mammalian two-hybrid assays five peptide aptamers interacted with Ids. Peptide aptamer Id1-PA5 and Id1-PA17 interacted with Id1, peptide aptamer Id1/3-PA7 interacted with Id1 and Id3, peptide aptamer Id3-PA10 interacted with Id3 and peptide aptamer d1-4-PA13 interacted with all Ids (Id1-4). Bars: black, Id1, black dotted, Id2, hatched, Id3, white dotted, Id4. b, The five peptide aptamers did not interact with the binding partners of Ids. Bars: black, E47, black dotted, MyoD, hatched, ETS1, white dotted, ETS2 and white, S5A. Results are represented as mean values of three independent experiments with $\mathrm{SD}(\mathrm{P} \leq 0.05)$. 
Fig. 2 Peptide aptamer Id1/3-PA7 colocalizes to Id1 and Id3 and induces the E-box promoter activity. a-b, His-tag coimmunoprecipitation of Id1/3-PA7 with Id1 and Id3 in MCF7 and MDA-MB-231. c-d, His-tag coimmunoprecipitation of $\operatorname{TrxA}$ as negative control. e-f, Coimmunofluorescence staining of Id1/3-PA7 with Id1 and Id3 in MCF7. g, Id1/3-PA7 untreated MCF7 cells as negative control. h, Id1/3-PA7 induced E47 dependent E-box promoter activity. E47 upregulated the E-box dependent reporter gene (6), Id1 or Id3 reduced E47 dependent activation $(13,14)$ and addition of Id1/3-PA7 restored E47 dependent activation $(15,16)$. The control with TrxA showed no effect on the E-box promoter activity. Results are represented as mean values of three independent experiments with $\mathrm{SD}(\mathrm{P} \leq 0.05)$.

Fig. 3 Upregulation of CDKN1 A and CDKN1B expressions by Id1/3-PA7. a-b, Results of the quantitative real time PCR. Transduction of breast cancer cells MCF7 and MDA-MB-231 with Id1/3-PA7 caused dose dependent increase in relative mRNA level of CDKN1A and CDKN1B compared to that in untreated or TrxA treated $\left(5 \mu \mathrm{g} / 10^{6}\right.$ cells $)$ cells. The increased expression levels of CDKN1A and CDKN1B were counteracted by ectopically overexpressed Id1 and Id3. Black bars, MCF7 and hatched bars, MDA-MB-231. Results are represented as mean values of three independent experiments with $\mathrm{SD}(\mathrm{P} \leq 0.05)$. c-d, Western blotting showed increased CDKN1A and CDKN1B protein levels in Id1/3-PA7 treated $\left(5 \mu \mathrm{g} / 10^{6}\right.$ cells) MCF7 and MDA-MB-231 cells compared to that in untreated or TrxA treated $\left(5 \mu \mathrm{g} / 10^{6}\right.$ cells) cells. 
Fig. 4 Cell cycle arrest and apoptosis induced by Id1/3-PA7 in breast cancer cells. a-j, Measurement of cell incorporated BrdU (with FITC anti-BrdU) and total DNA content (with 7-AAD) in untreated and TrxA treated $\left(5 \mu \mathrm{g} / 10^{6}\right.$ cells) or Id1/3-PA7 treated $\left(5 \mu \mathrm{g} / 10^{6}\right.$ cells $)$ MCF7 cells (a-c) and MDA-MB-231 cells (d-f) respectively. After treatment in $4 \mathrm{~h}$ intervals for $48 \mathrm{~h}$ cells were prolonged cultured with $10 \mu \mathrm{M}$ BrdU for $6 \mathrm{~h}$. As demonstrated by the region gates applied to the 7-AAD versus BrdU dot plot, flow cytometric analysis of untreated cells versus Id1/3-PA7 treated cells showed that the antiproliferative and apoptotic effects of Id1/3-PA7 reduced the number of actively cycling cells in S from $92.1 \%$ to $51.1 \%$ for MCF7 cells (g) and from $92.5 \%$ to $53.5 \%$ for MDA-MB-231 cells (i). The number of apoptotic cells in sub G0/G1 and in G0/G1 or in G2/M resided cells increased from $2.1 \%$ to $15 \%$, from $3.9 \%$ to $19 \%$ and from $0.3 \%$ to $5.3 \%$ respectively for MCF7 cells (h ) and from $0.9 \%$ to $13 \%$, from $2.7 \%$ to $18.1 \%$ and from $0.4 \%$ to $7.6 \%$ respectively for MDA-MB-231 cells $(\mathrm{j})$. There were no significant differences between results of untreated and TrxA treated cells. (a-j). Bars in i and j: black, untreated; hatched, TrxA treated; white dotted, Id1/3-PA7 treated. Results are represented as mean values of three independent experiments with SD (P $\leq 0.05)$

Fig. 5 Effect of Id1/3-PA7 on PARP cleavage. a-b, Untreated and TrxA or Id1/3-PA7 treated MCF7 and MDA-MB-231 cells were analysed for PARP cleavage by western blotting. PARP cleavage was detected in cell extracts of Id1/3-PA7 treated cells. c-d, Ectopically overexpressed Id1 and Id3 inhibited Id1/3-PA7 dependent PARP cleavage. 
Fig. 1
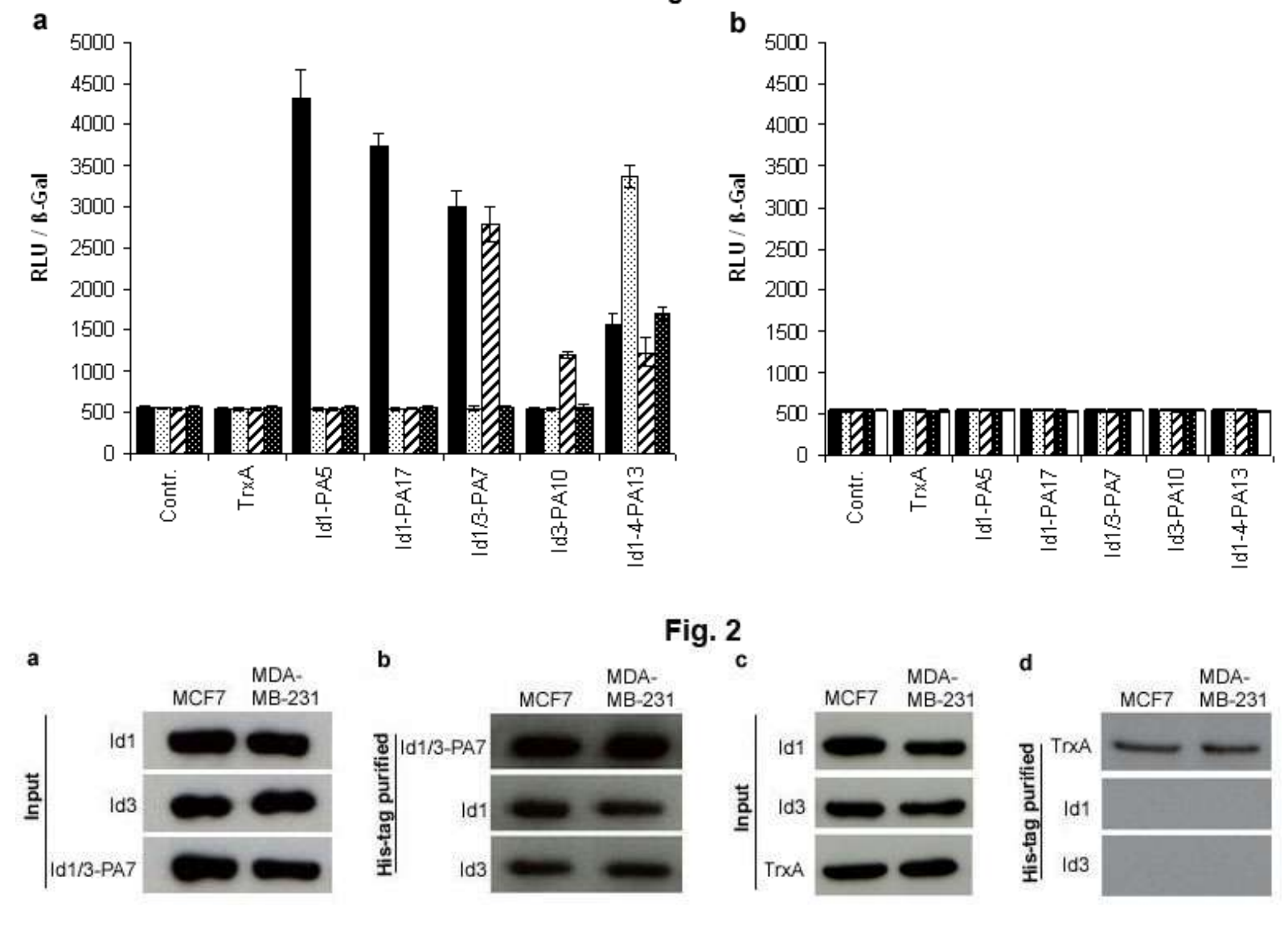

b MDA-

Fig. 2
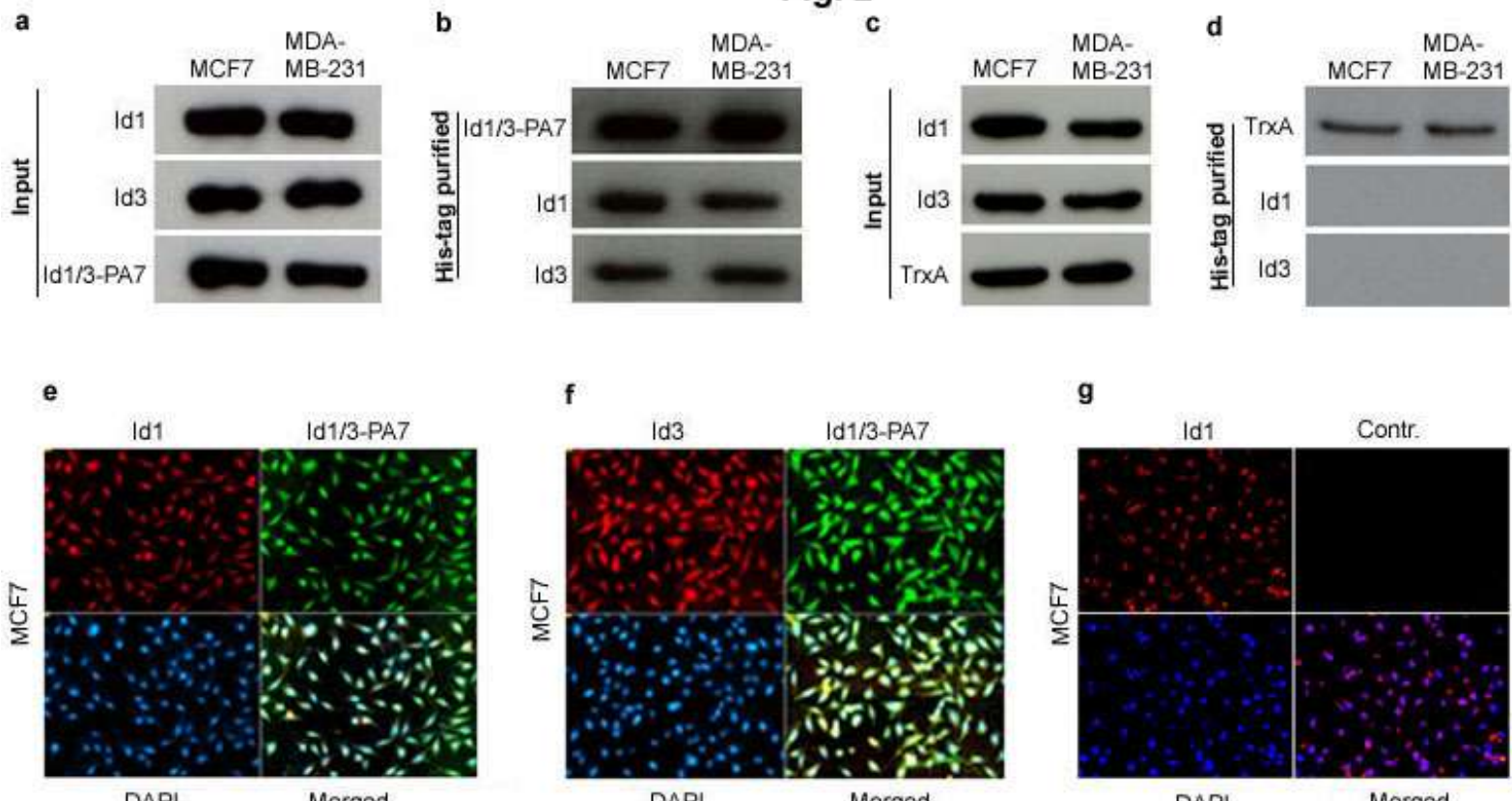

DAPI Merged

DAPI

Merged

DAPI

Merged

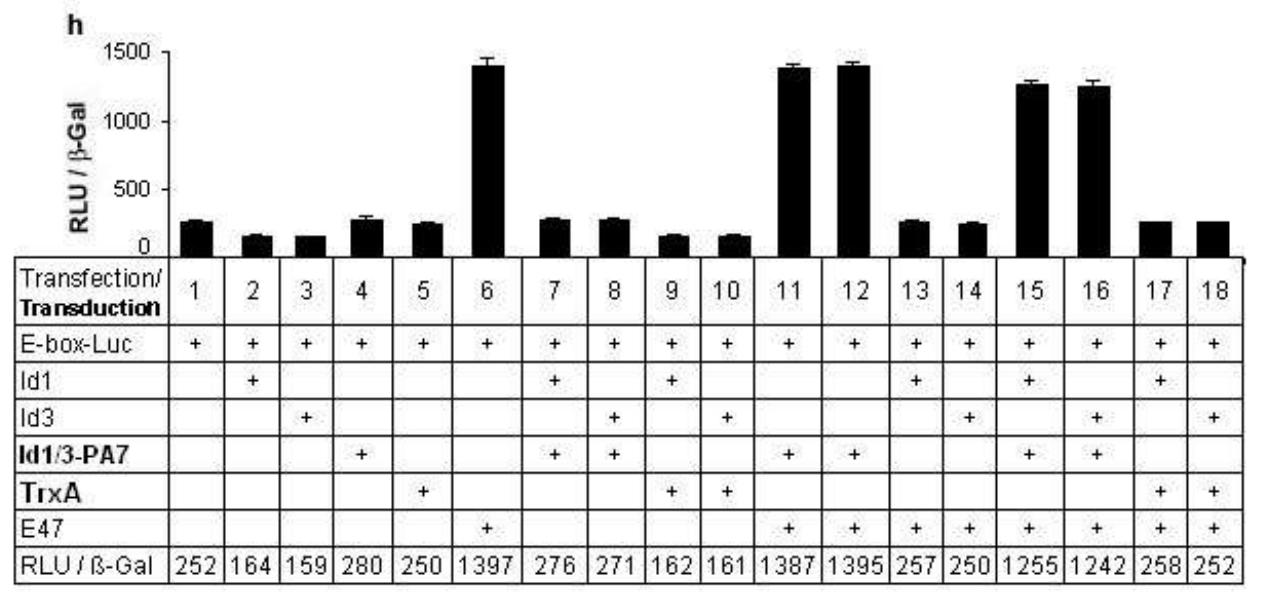



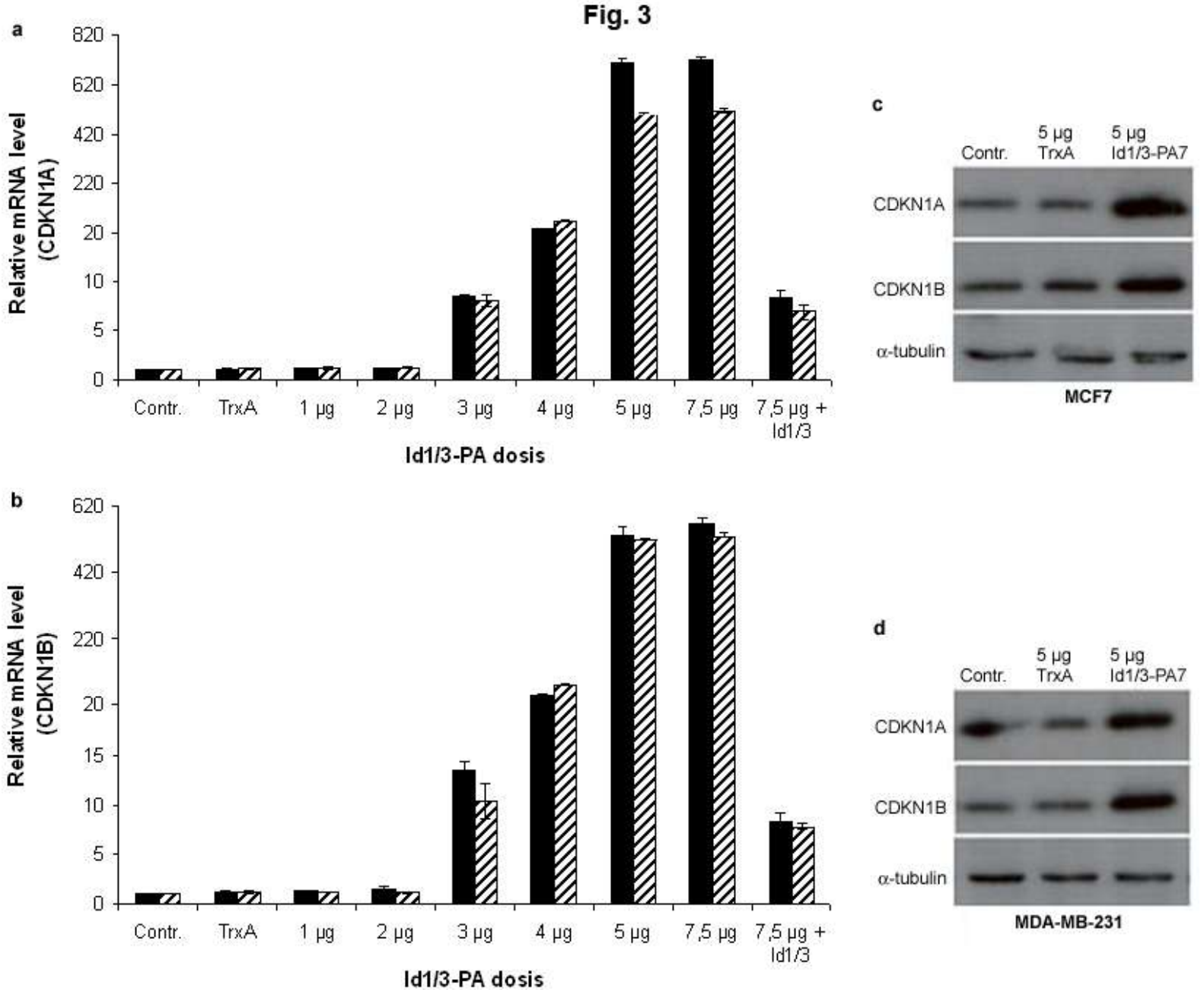

d

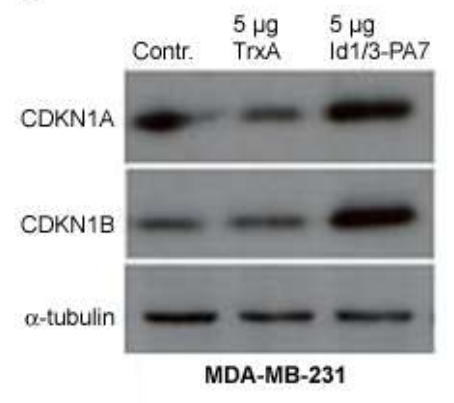


Fig. 4
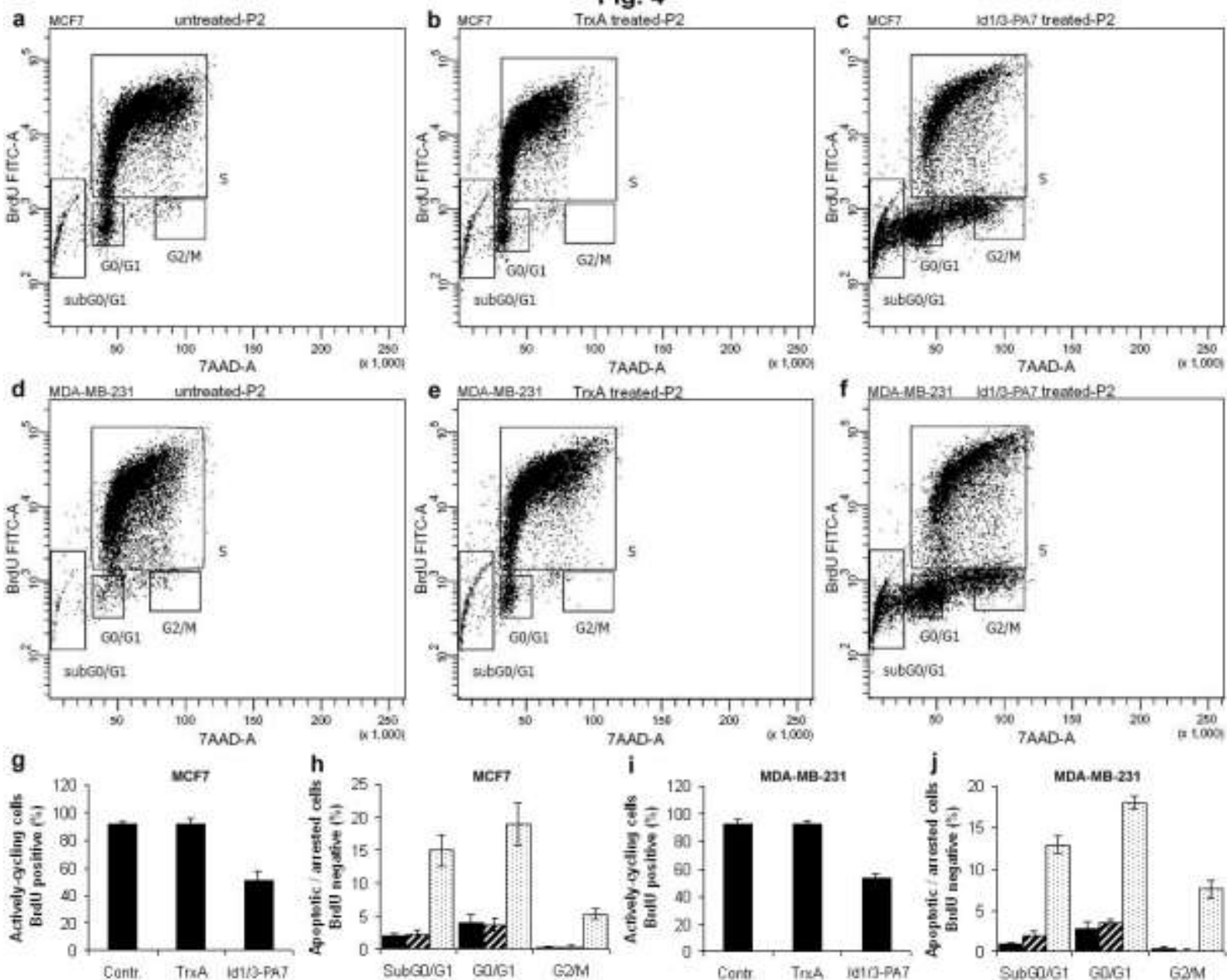

Fig. 5

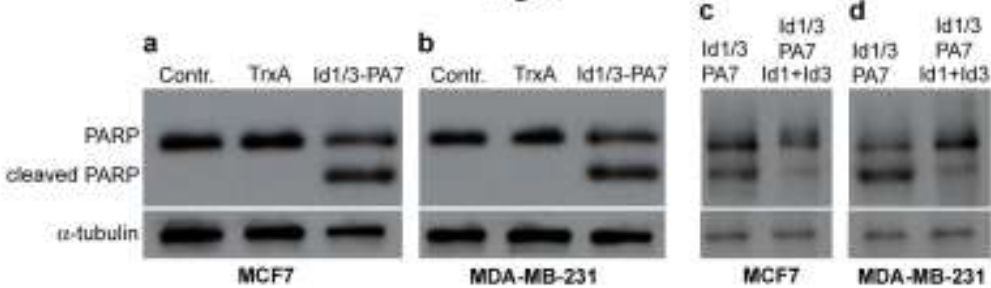

Tab. 1

\begin{tabular}{|c|c|c|c|c|c|}
\hline \multirow{2}{*}{$\begin{array}{l}\text { Peptide } \\
\text { aptamers (PA) }\end{array}$} & \multicolumn{4}{|c|}{ Interactions with Id proteins } & \multirow{2}{*}{ Sequences of the peptide aptamers } \\
\hline & Id1 & $\mathrm{Id} 2$ & $\mathrm{Id} 3$ & pPC97 & \\
\hline PA1 & + & - & - & - & GWSLGINDSRAPASWCGSSC \\
\hline PA2 & + & - & - & - & SRYIGLVIMLDDDKWFDARW \\
\hline PA3 & + & - & - & - & TRRPTPRRRRTRVINTQRPT \\
\hline PA4 & + & - & - & - & LLFELVDYSSFHPYCALSNS \\
\hline PA5 & + & - & - & - & GRVISWRGGSRCDSCSMAIW \\
\hline PA6 & + & - & + & - & RLAYGLVPRRYYRCRNVTLR \\
\hline PA7 & + & - & + & - & LSAMAATLFAELGCHLSRWM \\
\hline PA8 & + & - & + & - & CFLITCWWLTR YGFNTLRLR \\
\hline
\end{tabular}




\begin{tabular}{|c|c|c|c|c|c|}
\hline PA9 & + & - & + & - & FMCRLVLRLPFFCLVRS \\
\hline PA10 & + & - & + & - & VGCGSVASSFVSCCAFWACGGSVQNDRPDSG \\
\hline PA11 & + & - & - & - & PRFIPWRGISRCPSNSMSIW \\
\hline PA12 & + & - & - & - & GLWVLMTRVRLRRGVGRR \\
\hline PA13 & + & - & + & - & VVILGWLLCWMMISSFRLGW \\
\hline PA14 & + & - & - & - & SIALLRVTSLRRTPFRRFFL \\
\hline PA15 & + & - & - & - & VICLGVLRKAVVR \\
\hline PA16 & + & - & - & - & SHSCMQPFGVLWRGWGWFVM \\
\hline PA17 & + & - & - & - & CESFGLRLGSNFTWILN \\
\hline PA18 & + & - & - & - & PLDFVAYGLRYVSWRWWGWS \\
\hline PA19 & + & - & - & - & RLPAVDLFSPLSAVVVFVFLVRAK \\
\hline PA20 & + & - & - & - & IFRGWLVTRVN \\
\hline PA21 & + & - & - & - & QLWSLCEAGCDF \\
\hline PA22 & + & - & - & - & ILVPMSPFLLPTVSGLVGRM \\
\hline PA23 & + & - & - & - & SHSCMQPFGVL \\
\hline PA24 & + & - & - & - & IFAVPYRLVGFCRFVLVGFG \\
\hline PA25 & + & - & - & - & CFFLSPENLAAGFLRFDGALGPGWFHWANRADVHTG \\
\hline PA26 & + & - & - & - & AVSVASGYYAFSLGLCGGFV \\
\hline PA27 & + & - & - & - & HDDPHHDAGARESLIPKDQM \\
\hline PA28 & + & - & - & - & GKLLRQVTAAEHCTLR \\
\hline PA29 & + & - & - & - & WGMLWRRRGVIANFAGR \\
\hline PA30 & + & + & - & - & WVIGSWILWWRMISTFVLRM \\
\hline pADtrx & - & - & - & - & \\
\hline
\end{tabular}

